OPEN ACCESS

Edited by:

Xing Fu,

Louisiana State University Agricultural

Center, United States

Reviewed by:

Xiang Zhou,

Huazhong Agricultural

University, China

Lupei Zhang,

Chinese Academy of Agricultural

Sciences, China

Junxing Zhao,

Shanxi Agricultural University, China

${ }^{*}$ Correspondence: Jinming You

youjinm@jxau.edu.cn

tThese authors have contributed equally to this work

Specialty section:

This article was submitted to Nutrition and Metabolism,

a section of the journal

Frontiers in Nutrition

Received: 22 September 2020

Accepted: 27 October 2020

Published: 30 November 2020

Citation:

He Q, Zou T, Chen J, Jian L, He J, Xia Y, Xie F, Wang Z and You J (2020) Maternal Methyl-Donor Micronutrient

Supplementation During Pregnancy Promotes Skeletal Muscle Differentiation and Maturity in Newborn and Weaning Pigs. Front. Nutr. 7:609022

doi: 10.3389/fnut.2020.609022

\section{Maternal Methyl-Donor Micronutrient Supplementation During Pregnancy Promotes Skeletal Muscle Differentiation and Maturity in Newborn and Weaning Pigs}

\author{
Qin $\mathrm{He}^{1,2+}$, Tiande Zou ${ }^{1,2+}$, Jun Chen ${ }^{1,2}$, Li Jian ${ }^{1,2}$, Jia He ${ }^{1,2}$, Yingying Xia ${ }^{1,2}$, Fei Xie ${ }^{1,2}$, \\ Zirui Wang ${ }^{1,2}$ and Jinming You ${ }^{1,2 *}$ \\ ${ }^{1}$ Key Laboratory of Animal Nutrition in Jiangxi Province, Jiangxi Agricultural University, Nanchang, China, ${ }^{2}$ Key Innovation \\ Center for Industry-Education Integration of High-Quality and Safety Livestock Production in Jiangxi Province, Nanchang, \\ China
}

Adequate maternal methyl-donor micronutrient (MET) intake is an important determinant of the organ development and metabolic renovation of offspring. The mechanism involved in skeletal myogenesis and the effect of MET supplementation during pregnancy on the maternal body remain unclear. Thus, this study aimed to investigate the potential effect of methyl donor micronutrients (MET) on skeletal muscle development and metabolism in offspring using pig models. Forty-three Duroc $\times$ Erhualian gilts were assigned to two dietary groups during gestation: control diet $(\mathrm{CON})$ and $\mathrm{CON}$ diet supplemented with MET (folic acid, methionine, choline, vitamin B6, and vitamin B12). The results showed that maternal MET exposure during pregnancy significantly increased the concentrations of protein, triiodothyronine (T3), and thyroxine (T4) in colostrum and methyl metabolites, including S-adenosylmethionine (SAM), S-adenosyl-L-homocysteine (SAH), 5-methyl-tetrahydrofolate (5-MTHF), and betaine, in the maternal and offspring umbilical vein serum. A similar pattern was demonstrated in the body weight gain and myofiber diameters in offspring. In addition, maternal MET supplementation significantly increased the concentration of offspring serum insulin-like growth factor 1 (IGF-1), T3, and T4; upregulated the mRNA expression of IGF-1 and IGF-1 receptor (IGF-1r) and the phosphorylation level of protein kinases in offspring longissimus dorsi muscle; and upregulated the expression of myogenic genes and fast myosin heavy chain (fast MyHC) in offspring skeletal muscle. Supplementing sows with higher levels of MET during gestation may promote skeletal muscle differentiation and maturity and improve the skeletal muscle mass of the piglets.

Keywords: pregnancy, colostrum, offspring, myogenesis, muscle differentiation 


\section{INTRODUCTION}

Maternal nutrition during pregnancy plays a role in regulating offspring growth, development, and metabolic health through altering the epigenetic state of the genome (1-3). Previous studies showed that maternal methyl donor micronutrients (MET), such as folic acid, methionine, choline, betaine, etc., are associated with the structure, physiology, and metabolism of the offspring (4-7). MET participates in the synthesis of nucleotides, proteins, and lipids by integrating glucose, amino acid status, and vitamins and feeds into epigenetic mechanisms by methyl group donation or transfer (8). Recently, a study found that maternal MET supplementation has a significant effect on carcass traits and meat quality of pig offspring (9). The mechanism involved in skeletal myogenesis and the effect of MET supplementation during pregnancy on the maternal body remain unclear.

Skeletal muscle is one of the important peripheral tissues affected by maternal diets. It comprises $\sim 40 \%$ of the body mass (10). The net number of skeletal muscle fibers is determined during embryogenesis, and postnatal growth is mainly determined by an increase in the fiber size. Therefore, fetal growth stages are important for skeletal muscle development and could profoundly influence postnatal skeletal muscle growth processes of the offspring (3). Myogenesis is crucial in postnatal muscle growth and regeneration (11), which needs some nutrients; the suppression factor in this process is the usability of maternal nutrients (12). Public health policies recommend periconceptional maternal supplementation of methyl donor, especially in the first trimester of pregnancy. MET is usually provided as supplements during pregnancy to promote cell division during organ growth and the development and metabolic renovation of tissues (13). Methyl donor insufficiency constitutes a risk factor for weaned pups in growth retardation, delayed ossification, and cognitive deficits (14). Previous studies have mainly focused on the impact of methyl donor on neural tube defect, metabolism, and human and mouse offspring diseases (15-17). Recently, some studies have shown that the accumulation of methyl donor in cells is beneficial in improving muscle mass and betaine has a significant effect on skeletal myogenesis, such as proliferation and differentiation of myoblast in vitro and in vivo (18). In addition, it was reported that maternal MET could regulate growth and proliferation of pig offspring, which was at least partly mediated by insulin-like growth factor 1 (IGF-1) (19). The same effect has been shown in humans (20). However, whether a high level of maternal MET is related to a healthy skeletal muscle mass in offspring remains inconclusive.

Considering the similarities in the anatomical structure and metabolism between pigs and humans, the current study used pig as a translational model for the human infant. Therefore, this study aimed to evaluate whether maternal higher MET supplementation during gestation affects the skeletal muscle developmental characteristics and muscle fiber transform of pig offspring at birth and weaning.

\section{MATERIALS AND METHODS}

\section{Ethical Statement}

The experiment was conducted following the Chinese guidelines for animal welfare. All experimental procedures using laboratory animals were approved by the Animal Care and Use Committee of Jiangxi Agricultural University (Ethics Approval Code: JXAUA01).

\section{Experimental Design and Animal Material}

A total of 43 gilts (Duroc $\times$ Erhualian) with initial body weight (BW) of $102.8 \pm 6.3 \mathrm{~kg}$ and the same genetic background were artificially inseminated with purebred Duroc semen (littermate Duroc boars) and then randomly assigned to receive either a control diet (CON, $n=21)$ or a methyl donor micronutrient diet (MET, $n=22$ ). Dietary treatment started at the last insemination and lasted until parturition. Ingredients and composition of pregnant gilts diets are shown in Table 1. The nutrient levels met or exceeded the recommendation of the National Research Council (NRC) (2012) (21). The difference between the two diets was that the MET supplementation was replaced by the filler (wheat middlings) in the CON diet. After producing each diet, the main dietary nutritional contents were analyzed by the near-infrared (NIR) analyzer (FOSS, Denmark). There were no differences between the two groups in crude protein, crude ash, crude fat, crude fiber, calcium, and total phosphorus. The MET-supplemented gestation diet contained $4,700 \mathrm{mg} \mathrm{kg}^{-1}$ methionine (CJ BIO, Malaysia, purity $\geq 99 \%$ ), $16.3 \mathrm{mg} \mathrm{kg}^{-1}$ folic acid (Sigma-Aldrich, St. Louis, MO, United States, purity $\geq 97 \%$ ), 2,230 $\mathrm{mg} \mathrm{kg}^{-1}$ choline (NB GROUP, Shandong, China, purity $=60 \%$ ), $0.15 \mathrm{mg} \mathrm{kg}^{-1}$ vitamin B12 (Sigma-Aldrich, purity $\geq 98 \%$ ), and $1,180 \mathrm{mg} \mathrm{kg}^{-1}$ of vitamin B6 (Jiangxi Tianxin Pharmaceutical, Jiangxi, China, purity $\geq 98 \%$ ). Previous reports were used as references to determine the treatment dosages of folic acid (22), vitamin B12 $(9,23)$, methionine, choline, and vitamin B6 $(19,24)$. During lactation, sows received a standard lactation diet (Table 2). Lactation lasted 24 days. The experiment began with 54 gilts, 27 gilts per treatment. Pregnancy was confirmed by ultrasonic examination 30 days post-mating; 11 gilts were eliminated due to failure of pregnancy.

During gestation, all sows were housed per group with individual feeding. Sows were fed twice per day at 08:00 and 14:00 $\mathrm{h}$, and water was provided ad libitum. The feeding amount was based on regular breeding management of pig farm and NRC recommendations (2012). After 110 days of gestation, sows were transferred to farrowing pens. After parturition, all sows were fed on the diet three times per day (i.e., 08:00, 12:00, and 15:00 h). Freshwater was provided ad libitum. During the first 5 days of lactation, the amount of feed was progressively increased. Subsequently, lactating sows were fed ad libitum until weaning at 24 days.

\section{Sample Collection}

After 110 days post-conception, blood samples of sows were collected via the precaval vein at $07: 00 \mathrm{~h}$ immediately before feeding. During parturition, colostrum samples $(30-40 \mathrm{~mL})$ were 
TABLE 1 | Ingredients and nutrient composition of diets for the pregnant sows.

\begin{tabular}{|c|c|c|}
\hline Items & CON & MET \\
\hline \multicolumn{3}{|l|}{ Ingredients, \% } \\
\hline Corn & 55.00 & 55.00 \\
\hline Soybean hull & 10.00 & 10.00 \\
\hline Rice bran & 10.00 & 10.00 \\
\hline Expanded soybean & 8.00 & 8.00 \\
\hline Soybean meal & 13.00 & 13.00 \\
\hline Dicalcium phosphate & 1.70 & 1.70 \\
\hline Limestone & 0.20 & 0.20 \\
\hline $\mathrm{NaCl}$ & 0.30 & 0.30 \\
\hline Lysine monohydrochloride, 98.5\% & 0.05 & 0.05 \\
\hline Choline chloride, $60 \%$ & 0.17 & 0.17 \\
\hline Minerals $^{a}$ & 0.40 & 0.40 \\
\hline Vitamins $^{a}$ & 0.05 & 0.05 \\
\hline Methyl donnorb & 0 & 1.11 \\
\hline Filler $^{\mathrm{c}}$ & 1.13 & 0.02 \\
\hline Total & 100.00 & 100.00 \\
\hline \multicolumn{3}{|l|}{ Calculated nutrient composition ${ }^{b}$} \\
\hline Digestible energy, Mcal kg-1 & 3.14 & 3.14 \\
\hline Crude protein, \% & 15.20 & 15.20 \\
\hline Total lysine, \% & 0.86 & 0.86 \\
\hline Standardized ideal digestible- Iysine, \% & 0.72 & 0.72 \\
\hline Calcium, \% & 0.86 & 0.86 \\
\hline Total phosphorus, \% & 0.69 & 0.69 \\
\hline Available phosphorus, \% & 0.41 & 0.41 \\
\hline Folic acid, $\mathrm{mg} \mathrm{kg}^{-1}$ & 1.30 & 16.30 \\
\hline Choline, $\mathrm{mg} \mathrm{kg}^{-1}$ & 1025.00 & 2230.00 \\
\hline Vitamin B12, $\mu \mathrm{g} \mathrm{kg}^{-1}$ & 30.00 & 150.00 \\
\hline Vitamin B6, mg kg-1 & 3.00 & 1180.00 \\
\hline Methionine, $\mathrm{mg} \mathrm{kg}^{-1}$ & 2050.00 & 4700.00 \\
\hline \multicolumn{3}{|l|}{ Nutrient composition, $\% d$} \\
\hline Crude protein & 15.26 & 15.22 \\
\hline Crude ash & 5.96 & 5.92 \\
\hline Crude fat & 5.63 & 5.57 \\
\hline Crude fiber & 5.23 & 5.38 \\
\hline Calcium & 0.94 & 0.98 \\
\hline Total phosphorus & 0.64 & 0.64 \\
\hline
\end{tabular}

a Vitamin mixture supplied the following amounts of vitamins $/ \mathrm{kg}$ of complete diet: 10,000 U vitamin A; 1,000 U vitamin D3; 60 IU vitamin E; $2 \mathrm{mg}$ vitamin B1; $4 \mathrm{mg}$ vitamin B2; $3 \mathrm{mg}$ niacin; $15 \mathrm{mg} \mathrm{Cu} ; 110 \mathrm{mg}$ Fe; $100 \mathrm{mg} \mathrm{Zn;} 20 \mathrm{mg} \mathrm{Mn;} 0.2 \mathrm{mg}$ I; $0.3 \mathrm{mg} \mathrm{Se}$.

${ }^{b}$ Calculated according to the China Feed Database.

${ }^{c}$ The filler was wheat middlings $(C F=2.8 \%, C P=13.6 \%, D E=3.1 \mathrm{Mcal} / \mathrm{kg})$.

${ }^{d}$ The nutrient composition is measured value.

collected from sows by hand milking after thoroughly cleaning the udder with water before newborns suckled. Besides, umbilical vein blood was collected from all sows. The colostrum and serum samples were immediately refrigerated at $-20^{\circ} \mathrm{C}$ for further testing. The $\mathrm{BW}$ of each piglet was recorded after cleaning the fetal membrane. A total of 12 piglets/treatment (half male and half female) were, respectively, selected from $12 \mathrm{~L}$ according to the BW (as close as possible to the average BW in each treatment group). Venous blood samples were collected from piglets that
TABLE 2 | Ingredients and nutrient composition of basal diets during lactation.

\begin{tabular}{|c|c|}
\hline Items & Content \\
\hline \multicolumn{2}{|l|}{ Ingredients \% } \\
\hline Corn & 59.00 \\
\hline Rice bran & 7.00 \\
\hline Soybean meal & 22.00 \\
\hline Fermented soybean meal & 4.00 \\
\hline Soybean oil & 2.00 \\
\hline Fish meal & 2.00 \\
\hline Dicalcium phosphate & 1.40 \\
\hline Limestone & 1.20 \\
\hline $\mathrm{NaCl}$ & 0.30 \\
\hline Lysine monohydrochloride, 98.5\% & 0.05 \\
\hline Choline chloride, $60 \%$ & 0.17 \\
\hline Minerals $^{a}$ & 0.20 \\
\hline Vitamins $^{a}$ & 0.20 \\
\hline Filler ${ }^{b}$ & 0.48 \\
\hline Total & 100.00 \\
\hline \multicolumn{2}{|l|}{ Calculated nutrient composition ${ }^{c}$} \\
\hline Digestible energy, Mcal kg-1 & 3.30 \\
\hline Crude protein, \% & 18.46 \\
\hline Total lysine, \% & 1.05 \\
\hline Standardized ideal digestible-lysine, \% & 0.92 \\
\hline Standardized ideal digestible-methionine, \% & 0.27 \\
\hline Standardized ideal digestible-threonine, \% & 0.62 \\
\hline Standardized ideal digestible-tryptophan, \% & 0.20 \\
\hline Calcium, \% & 0.93 \\
\hline Total phosphorus, \% & 0.73 \\
\hline Available phosphorus, \% & 0.43 \\
\hline \multicolumn{2}{|l|}{ Nutrient composition, $\%^{\mathrm{d}}$} \\
\hline Crude protein & 18.86 \\
\hline Crude ash & 6.25 \\
\hline Crude fat & 4.44 \\
\hline Crude fiber & 4.05 \\
\hline Calcium & 0.98 \\
\hline Total phosphorus & 0.69 \\
\hline
\end{tabular}

a Vitamin mixture supplied the following amounts of vitamins $/ \mathrm{kg}$ of complete diet: 7,000 IU vitamin $A ; 1500$ IU vitamin D3; 16 IU vitamin E; $1 \mathrm{mg}$ vitamin $B 1 ; 2.4 \mathrm{mg}$ vitamin $B 2$; $1 \mathrm{mg}$ vitamin B6; $8 \mu \mathrm{g}$ vitamin B12; $20 \mathrm{mg}$ niacin; $0.6 \mathrm{mg}$ folic acid; $16 \mathrm{mg} \mathrm{Cu;} 100 \mathrm{mg}$ $\mathrm{Fe} ; 80 \mathrm{mg} \mathrm{Zn;2mg} \mathrm{Mn;0.14mg} \mathrm{l;} 0.1 \mathrm{mg}$ Se.

${ }^{b}$ The filler was wheat middlings (CF $=2.8 \%, C P=13.6 \%, D E=3.1 \mathrm{Mcal} / \mathrm{kg}$ ).

${ }^{\text {CC}}$ Calculated according to the China Feed Database.

${ }^{d}$ The nutrient composition is measured value.

were not fed on colostrum, and then the longissimus dorsi muscles were immediately collected after euthanasia, snap-frozen in liquid nitrogen, and stored at $-80^{\circ} \mathrm{C}$ for further analyses. Longissimus dorsi samples for histological analysis were fixed in $4 \%$ paraformaldehyde in a phosphate buffer. Similarly, a total of 8 weaned piglets/treatment (half male and half female) were, respectively, selected from $8 \mathrm{~L}$ according to the $\mathrm{BW}$ (as close as possible to the average $\mathrm{BW}$ in each treatment group). The samples collected from the weaned piglets were similar to those of the newborn piglets. 


\section{Serum and Colostrum Hormone Measurement}

Serum from sows at day 110 and offspring umbilical cord was analyzed for S-adenosylmethionine (SAM), Sadenosyl-L-homocysteine (SAH), homocysteine (Hcy), 5-methyl-tetrahydrofolate (5-MTHF), and betaine using the enzyme-linked immunosorbent assay (ELISA) kits purchased from MLBIO (Shanghai, China). Sensitivities of the assays were $0.1 \mu \mathrm{mol} / \mathrm{mL}, 0.1 \mu \mathrm{mol} / \mathrm{mL}, 0.1 \mathrm{nmol} / \mathrm{mL}, 0.1 \mathrm{ng} / \mathrm{mL}$, and $1.0 \mathrm{ng} / \mathrm{mL}$ for SAM, SAH, Hcy, 5-MTHF, and betaine, respectively. Intra- and inter-assay coefficients of variation (CV) were $<10$ and $15 \%$, respectively. Serum IGF-1, triiodothyronine (T3), and thyroxine (T4) of newborn and weaning piglets were assessed using ELISA kits purchased from Nanjing Jiancheng Biotech (Nanjing, China). Sensitivities of the assays were 0.5 $\mu \mathrm{g} / \mathrm{L}, 1.5 \mathrm{pmol} / \mathrm{L}$, and $12.5 \mathrm{pmol} / \mathrm{L}$ for IGF-1, T3, and T4, respectively. The intra- and inter-assay $\mathrm{CV}$ was $<10$ and $12 \%$, respectively.

\section{Colostrum Composition Analysis}

All colostrum samples were analyzed for moisture, total solids (TS), solid non-fat (SNF), lactose protein, and fat content. Colostrum prolactin was assessed with ELISA kits purchased from Nanjing Jiancheng Biotech (Nanjing, China). The sensitivity of the assay was $2 \mathrm{ng} / \mathrm{L}$, and the intra- and inter-assay CV was $<10$ and $12 \%$, respectively. Colostrum immunoglobulins (Ig), T3, and T4 were determined by immunoturbidimetry and ELISA kits purchased from Sino-UK (Beijing, China). Sensitivities of the assays were $0.1 \mathrm{~g} / \mathrm{L}, 0.1 \mathrm{~g} / \mathrm{L}$, $0.1 \mathrm{~g} / \mathrm{L}, 0.05 \mathrm{ng} / \mathrm{mL}$, and $1 \mathrm{ng} / \mathrm{ml}$ for immunoglobulin $\mathrm{G}(\mathrm{IgG})$, $\operatorname{IgA}, \operatorname{IgM}, \mathrm{T} 3$, and T4, respectively. The intra- and inter-assay $\mathrm{CV}$ was $<4.5$ and $9.5 \%$, respectively, for immunoglobulins and 10 and $12 \%$, respectively, for $\mathrm{T} 3$ and $\mathrm{T} 4$.

\section{Histological Analysis}

Longissimus dorsi muscle samples were embedded in paraffin, sliced at a thickness of $6 \mu \mathrm{m}$, and stained with hematoxylin and eosin (H\&E). More than ten different microscopic fields of each section were chosen to determine the cross-sectional area of muscle fibers and calculate the muscle fiber density.

\section{Quantitative Real-Time PCR}

Total RNA was isolated from the muscle tissue using TRIzol reagent (TransGen Biotech, Beijing, China). The integrity, purity, and concentration of RNA were determined by $1 \%$ agarose gel electrophoresis and nucleic acid/protein analyzer. cDNA was synthesized with a commercial RT Master Mix kit (TransGen). qPCR amplification was performed with the BioRad PCR machine with SYBR green master mix (TransGen) following the manufacturer's guidelines. All samples were analyzed in triplicates. The optimal annealing temperature of each primer was determined. The correlation coefficients of all the standard curves were $>0.99$, and the amplification efficiency values were between 90 and 110\% (3.6>slope $>3.1$ ). The specificity of amplification was determined by the melting curve analysis at the end of the target gene amplification. The relative mRNA expression of target genes was determined after
TABLE 3 | Primer sequences of the target genes and reference genes.

\begin{tabular}{|c|c|c|c|}
\hline Gene & Primer sequence $\left(5^{\prime}-3^{\prime}\right)$ & $\begin{array}{l}\text { Product } \\
\text { (bp) }\end{array}$ & GenBank ID \\
\hline \multirow[t]{2}{*}{ IGF1 } & Forward: TTCAACAAGCCCACAGGGTA & 102 & XM_005664199.1 \\
\hline & Reverse: CTCCAGCCTCCTCAGATCAC & & \\
\hline \multirow[t]{2}{*}{ IGF-1r } & Forward: ATTACCGCAAGGGAGGGAAA & 174 & NM_214172.1 \\
\hline & Reverse: GAAGGACTTGCTCGTTGGAC & & \\
\hline \multirow[t]{2}{*}{ AKT1 } & Forward: CTGCCСTTCTACAACCAGGA & 66 & HQ687753.1 \\
\hline & Reverse: GAAGCGGATCTCCTCCATGA & & \\
\hline \multirow[t]{2}{*}{ AKT2 } & Forward: GTGCTTCGTGATGGAGTACG & 118 & HQ687754 \\
\hline & Reverse:C TCCAGAGCCGAGACAATCT & & \\
\hline \multirow[t]{2}{*}{ IGFBP5 } & Forward: GTGTACCTGCCCAACTGTGA & 158 & NM_214099.1 \\
\hline & Reverse: AAGCTGTGGCACTGGAAGTC & & \\
\hline \multirow[t]{2}{*}{ Myf5 } & Forward: AGACGCCTCAAGAAGGTCAA & 95 & NM_001278775.1 \\
\hline & Reverse: CTGAGGATCTCCACCTTGGG & & \\
\hline \multirow[t]{2}{*}{ Myf6 } & Forward: CCCTTCAGCTACAGACCCAA & 183 & NM_001244672.1 \\
\hline & Reverse: GTCCACGATGGAAGAAAGGC & & \\
\hline \multirow[t]{2}{*}{ MyOD1 } & Forward: GTGCAAACGCAAGACCACTA & 125 & NM_001002824.1 \\
\hline & Reverse: GATTCGGGTTGCTAGACGTG & & \\
\hline \multirow[t]{2}{*}{ Myog } & Forward: ААТСТGСАСТСССТСАССТС & 73 & NM_001012406.1 \\
\hline & Reverse: TTCATCTGGGAAGGCCACA & & \\
\hline \multirow[t]{2}{*}{ Pax3 } & Forward: CAGCAGAGCAGCTTGAAGAG & 152 & XM_021075359.1 \\
\hline & Reverse: CTGCTTCCTCСАTCTTGCAC & & \\
\hline \multirow[t]{2}{*}{ Pax7 } & Forward: TGCCCTCAGTGAGTTCGATT & 152 & NM_001206359.1 \\
\hline & Reverse: ATCCAGACGGTTCCCTTTGT & & \\
\hline \multirow[t]{2}{*}{ MRF4 } & Forward: CCCTTCAGCTACAGACCCAA & 183 & NM_001244672.1 \\
\hline & Reverse: GAGCAGCTGGAAGTAAAGGC & & \\
\hline \multirow[t]{2}{*}{ MSTN } & Forward: AGTGATGGCTCCTTGGAAGA & 169 & AY448008.2 \\
\hline & Reverse: TCCACAGTTGGGCCTTACT & & \\
\hline \multirow[t]{2}{*}{ TGF $\beta-1$} & Forward: GCAGGTACTCCTGGTGAACT & 196 & AF461808.1 \\
\hline & Reverse: AGGATACCAGTCGGGTAGGT & & \\
\hline \multirow[t]{2}{*}{ MYH7 } & Forward: TTCAAGCTGGAGCTGGATGA & 152 & NM_213855 \\
\hline & Reverse: GTGAGGTCGTTGACAGAACG & & \\
\hline \multirow[t]{2}{*}{ MYH2 } & Forward: TAGGCCCTITGATGCCAAGA & 111 & NM_214136 \\
\hline & Reverse: GCTTCCGTCTTCACTGTCAC & & \\
\hline \multirow[t]{2}{*}{ MYH1 } & Forward: TCAAGGACACCCAGATCCAC & 166 & NM_001104951 \\
\hline & Reverse: TCCTGTTCTGCGACTTTCCT & & \\
\hline \multirow[t]{2}{*}{ MYH4 } & Forward: GAATCCCTGGACCAACTGGA & 92 & NM_001123141 \\
\hline & Reverse: ССТСССТСТGСАATТGGСТ & & \\
\hline \multirow[t]{2}{*}{ GAPDH } & Forward: TGGAAAGGCCATCACCATCT & 105 & NM_001206359.1 \\
\hline & Reverse: ATGGTCGTGAAGACACCAGT & & \\
\hline
\end{tabular}

IGF1, insulin-like growth factor 1; IGF1, insulin-like growth factor 1 receptor; AKT, protein kinases; IGFBP5, insulin growth factor-binding protein 5; Myf5, myogenic factor 5; Myf6, myogenic factor 6; MyoD1, myogenic differentiation factor 1; Myog, myogenin; Pax3, paired box gene 3; Pax7, paired box gene 7; MRF4, muscle regulatory factor 4; MSTN, myostatin; TGF $\beta-1$, transforming growth factor $-\beta 1 ; M Y H$, myosin heavy chain; GAPDH, glyceraldehyde-3-phosphate dehydrogenase.

normalization of glyceraldehyde-3-phosphate dehydrogenase (GAPDH) reference using the $2^{-\Delta \Delta \mathrm{Ct}}$ method (25). The primer sequences of the target genes and GAPDH were designed by Primer 5.0 software (Premier Biosoft, Palo Alto, CA, United States) and validated by BLAST sequence alignment in NCBI (Table 3). 


\section{Immunoblotting Analysis}

Protein was extracted from muscle tissues with a total protein extraction kit (Beijing Solarbio Science \& Technology Co., Ltd., Beijing, China) according to the manufacturer's instructions. Protein concentration was measured using the bicinchoninic acid (BCA) protein assay kit (TransGen). The total protein was then denatured with a $6 \times$ protein loading buffer (TransGen). Western blot analysis for protein kinases (t-AKT; 9272S, Cell Signaling, United States), phosphorylated protein kinases (p-AKT; 9271S, Cell Signaling, United States), myogenic differentiation factor 1 (MyoD1; 18943-1-AP, Proteintech, China), myogenin (Myog) (ab1835, Abcam, United States), slow myosin heavy chain (slow MyHC; ab11083, Abcam, United States), fast MyHC (20140-1AP, Proteintech, China), and $\beta$-actin (66009-1-Ig, Proteintech, China) was carried out as previously described (12). Briefly, protein extracts were separated by $10 \%$ SDS-PAGE gels and transferred to a polyvinylidene difluoride (PVDF) membrane (Beijing Solarbio Science \& Technology Co., Ltd., Beijing, China). The membrane was washed with TBS with $0.1 \%$ Tween 20 (TBST) and incubated with 5\% non-fat dry milk in TBS with $0.1 \%$ TBST at room temperature for $60 \mathrm{~min}$, incubated overnight with the selected primary antibodies at $4^{\circ} \mathrm{C}$, and washed with TBST followed by incubation with either horseradish peroxidase (HRP)-conjugated goat anti-mouse or HRP-conjugated goat anti-rabbit secondary antibodies for $60 \mathrm{~min}$ at room temperature. Finally, membranes were visualized using the Image Lab statistical software (Bio-Rad, Laboratories, Hercules, CA, United States). The secondary antibodies were purchased from Proteintech Group (SA00001-1 and SA00001-2). The relative expressions of t-AKT, p-AKT, MyoD1, Myog, slow $\mathrm{MyHC}$, and fast $\mathrm{MyHC}$ protein were normalized to $\beta$-actin.

\section{Statistical Analyses}

Statistical analysis was performed using SPSS 24.0 software (SPSS Inc.). The Shapiro-Wilk test was performed to determine whether measured data sets followed a normal distribution. All data sets were normally distributed and required no transformation prior to analysis. The statistical power was adequate for detecting differences between groups. An independent-sample $t$-test was used to compare the differences between the CON and the MET. The individual sow was considered as the experimental unit for number of born and weaned piglets, and a litter was considered as the experimental unit for litter weight and daily gain weight, whereas each pig was considered as the experimental unit for the remaining data. All results are shown as means $\pm \mathrm{SD}$; a value of $P<0.05$ was considered statistically significant.

\section{RESULTS}

\section{Maternal Characteristics}

The reproductive performance of sows fed with the MET diet and the growth performance of offspring are shown in Table 4. There was no difference in the number of total born, born alive, and weaned piglets $(P>0.05)$. There was no significant difference in the litter weight of birth $(P>0.05)$. However, the litter weight at
TABLE 4 | Effect of maternal methyl-donor micronutrient (MET) supplementation during gestation on growth performance of offspring ( $n=21$ per group).

\begin{tabular}{lccc}
\hline Items & CON & MET & P-value \\
\hline No. of total born per litter & $10.75 \pm 2.14$ & $10.92 \pm 2.10$ & 0.840 \\
No. of born alive per litter & $10.58 \pm 2.07$ & $10.69 \pm 2.06$ & 0.896 \\
No. of weaned piglets per litter & $9.00 \pm 1.48$ & $9.36 \pm 1.63$ & 0.590 \\
Litter weight at birth, kg & $13.10 \pm 2.97$ & $13.99 \pm 2.05$ & 0.391 \\
Litter weight at weaning, kg & $58.09 \pm 8.27$ & $69.40 \pm 12.96$ & 0.024 \\
Average daily gain during 1-24 days & $0.23 \pm 0.03$ & $0.26 \pm 0.01$ & 0.005 \\
\hline
\end{tabular}

Data are reported as means \pm standard deviation. CON, control diet; MET, methyl-donor micronutrient diet.

TABLE 5 | Effect of maternal MET supplementation during gestation on nutrition composition, immunoglobulin, total triiodothyronine (T3), and thyroxine (T4) concentrations in colostrum ( $n=10$ per group).

\begin{tabular}{lccc}
\hline Items & CON & MET & $P$-value \\
\hline Nutrition composition, \% & & & \\
$\quad$ Moisture & $73.96 \pm 2.77$ & $72.45 \pm 4.23$ & 0.377 \\
TS & $13.89 \pm 2.21$ & $16.96 \pm 3.78$ & 0.069 \\
SNF & $8.71 \pm 0.49$ & $8.74 \pm 0.55$ & 0.922 \\
Fat & $3.27 \pm 0.31$ & $3.36 \pm 0.38$ & 0.603 \\
Lactose & $3.02 \pm 0.33$ & $2.91 \pm 0.37$ & 0.493 \\
Protein & $5.49 \pm 0.80$ & $6.88 \pm 1.36$ & 0.018 \\
Colostrum immunoglobulins, ng/L & & & \\
IgM & $3.18 \pm 0.25$ & $3.88 \pm 0.59$ & 0.023 \\
IgG & $60.75 \pm 6.38$ & $67.34 \pm 3.68$ & 0.060 \\
IgA & $11.11 \pm 0.79$ & $11.82 \pm 0.82$ & 0.156 \\
Colostrum hormones & & & \\
T3, ng/mL & & & \\
T4, ng/mL & $0.12 \pm 0.01$ & $0.15 \pm 0.02$ & 0.005 \\
T3/T4 & $4.49 \pm 0.94$ & $5.63 \pm 0.57$ & 0.007 \\
\hline
\end{tabular}

Data are reported as means \pm standard deviation. TS, total solids; SNF, solid-non-fat; Ig, immunoglobulin CON, control diet; MET, methyl-donor micronutrient diet.

weaning and average daily gain were greater in piglets from the MET sows compared with those from the CON sows $(P<0.05)$.

\section{Colostrum Composition of Sows}

Colostrum obtained from the MET-fed sows had a higher protein content than that from the CON-fed sows $(P<0.05)$. Colostrum from the MET-fed sows tended to have a greater TS than that from the CON-fed sows $(P=0.069)$. The IgM level was increased in colostrum from the MET sows compared with that from the CON sows $(P<0.05)$. Colostrum from the METfed sows tended to have a greater IgG level than that from the CON-fed sows $(P=0.060)$. T3 and T4 concentrations were significantly higher in the MET group colostrum compared with the CON group colostrum $(P<0.05)$. However, the ratio of T3 to T4 did not differ in the colostrum of the CON and the MET sows $(P>0.05$; Table 5$)$. Moreover, serum prolactin was higher in the supplemented sows than in the control sows $(P<0.05)$. However, there was no significant difference 
TABLE 6 | Effect of maternal MET supplementation during gestation on prolactin concentration in sows' serum and colostrum ( $n=10$ per group).

\begin{tabular}{lccc}
\hline Items & CON & MET & $P$-value \\
\hline Serum prolactin, ng/L & $220.85 \pm 37.20$ & $283.32 \pm 52.70$ & 0.034 \\
Colostrum prolactin, $\mathrm{ng} / \mathrm{L}$ & $102.46 \pm 35.01$ & $137.11 \pm 9.60$ & 0.099 \\
\hline
\end{tabular}

Data are reported as means \pm standard deviation. CON, control diet; MET, methyl-donor micronutrient diet.

TABLE 7 | Effect of maternal MET supplementation during gestation on the concentration of S-adenosylmethionine (SAM), S-adenosyl-L-homocysteine (SAH), homocysteine (Hcy), 5-methyl-tetrahydrofolate (5-MTHF), and betaine in sows and offspring umbilical vein serum ( $n=10$ per group).

\begin{tabular}{lccc}
\hline Items & CON & MET & P-value \\
\hline Sows & & & \\
SAM, $\mu \mathrm{mol} / \mathrm{mL}$ & $41.98 \pm 10.80$ & $73.63 \pm 15.86$ & 0.004 \\
SAH, $\mu \mathrm{mol} / \mathrm{mL}$ & $23.76 \pm 5.83$ & $37.17 \pm 7.06$ & 0.006 \\
Hcy, nmol/mL & $6.66 \pm 1.57$ & $4.42 \pm 0.66$ & 0.005 \\
5-MTHF, ng/mL & $19.45 \pm 8.51$ & $30.75 \pm 6.93$ & 0.030 \\
Betaine, $\mathrm{ng} / \mathrm{L}$ & $1.01 \pm 0.29$ & $2.13 \pm 0.45$ & 0.001 \\
Offspring umbilical vein & & & \\
SAM, $\mu \mathrm{mol} / \mathrm{mL}$ & $20.16 \pm 1.06$ & $22.67 \pm 1.89$ & 0.032 \\
SAH, $\mu \mathrm{mol} / \mathrm{mL}$ & $11.19 \pm 0.69$ & $12.24 \pm 0.36$ & 0.001 \\
Hcy, nmol/mL & $17.15 \pm 1.53$ & $15.01 \pm 1.26$ & 0.033 \\
5-MTHF, ng/mL & $3.70 \pm 0.22$ & $3.99 \pm 0.35$ & 0.037 \\
Betaine, ng/L & $0.37 \pm 0.03$ & $0.42 \pm 0.05$ & 0.003 \\
\hline
\end{tabular}

Data are reported as means \pm standard deviation. CON, control diet; MET, methyl-donor micronutrient diet.

in colostrum prolactin between these two groups $(P>0.05$; Table 6).

\section{Serum Methyl Metabolite Profile}

There was a significantly higher concentration of SAM in the sows and offspring umbilical vein of the MET group compared with the CON group $(P<0.05$; Table 7$)$. Similarly, serum concentrations of SAH, 5-MTHF, and betaine in the sows and offspring umbilical vein were higher in the treated group than in the control group $(P<0.05)$. However, the Hcy concentration in the sows and offspring umbilical vein serum was significantly decreased in the MET group $(P<0.05)$.

\section{Serum Hormone Profile}

Maternal MET supplementation during gestation increased serum IGF-1 concentration in the offspring at birth $(P<0.05$; Table 8). However, there was no significant difference in serum IGF- 1 concentration in the weaning pigs $(P>0.05)$. There was a significantly higher concentration of serum T3 and T4 in the weaning offspring of the MET group compared with the CON group $(P<0.05)$. The serum T3 concentration in piglets at birth and weaning was increased in the MET group $(P=0.066$, $P<0.05$, respectively). Furthermore, the maternal MET diet increased the ratio of T3 to T4 in the offspring serum at birth and weaning $(P<0.05)$.
TABLE 8 | Effects of maternal MET supplementation during gestation on serum concentration of insulin-like growth factor 1 (IGF-1), triiodothyronine (T3), and thyroxine (T4) in offspring ( $n=12$ at birth; $n=8$ at weaning).

\begin{tabular}{lccr}
\hline Items & CON & MET & P-value \\
\hline Birth & & & \\
IGF-1, $\mu \mathrm{g} / \mathrm{mL}$ & $23.76 \pm 2.02$ & $25.37 \pm 1.37$ & 0.048 \\
$\mathrm{~T} 3, \mathrm{ng} / \mathrm{mL}$ & $0.22 \pm 0.02$ & $0.36 \pm 0.06$ & 0.066 \\
T4, ng/mL & $0.99 \pm 0.27$ & $1.50 \pm 0.20$ & 0.001 \\
T3/T4 & $0.20 \pm 0.04$ & $0.16 \pm 0.02$ & 0.035 \\
Weaning & & & \\
IGF-1, $\mathrm{gg} / \mathrm{mL}$ & $26.17 \pm 1.80$ & $26.75 \pm 2.06$ & 0.569 \\
T3, ng/mL & $0.27 \pm 0.03$ & $0.38 \pm 0.06$ & 0.010 \\
T4, ng/mL & $1.15 \pm 0.27$ & $2.10 \pm 0.24$ & $<0.001$ \\
T3/T4 & $0.24 \pm 0.05$ & $0.16 \pm 0.02$ & 0.033 \\
\hline
\end{tabular}

Data are reported as means \pm standard deviation. CON, control diet; MET, methyl-donor micronutrient diet.

\section{Muscle Histological Analysis}

To determine whether MET exposure altered offspring skeletal muscle fiber size, we evaluated the cross-sectional fiber area of the longissimus dorsi muscle. H\&E staining showed that the diameter of the muscle fiber of the weaning pigs in the MET group was thicker than that of the CON group (Figure 1). The number of muscle fibers was decreased, and the muscle fiber cross-sectional area was increased in the weaning pigs with maternal MET dietary supplementation $(P<0.05)$. However, there was no variation in the offspring at birth.

\section{Expression of Muscle IGF Signaling Gene}

To further explore why maternal MET supplementation increased serum IGF-1 concentration in offspring at birth, we measured muscle IGF system genes mRNA expression and $\mathrm{t}$ $\mathrm{AKT}$ and $\mathrm{p}-\mathrm{AKT}$ protein expression in offspring at birth and weaning (Figure 2). Maternal dietary treatment had a significant effect on the mRNA abundance of the IGF signaling genes, including IGF-1 $(P<0.05)$, IGF-1r $(P<0.05)$, AKT1 $(P<0.05)$, and AKT2 $(P<0.05)$. A similar pattern was also demonstrated for gene expression of the longissimus dorsi muscle IGF-1 $(P<0.05)$ and AKT2 $(P<0.05)$ in the weaning pigs. Although the expression of total AKT protein level was not different, its phosphorylation was higher $(P<0.05)$ in MET supplemented offspring when compared to the CON group; the MET offspring had a significantly higher $\mathrm{p}-/ \mathrm{t}-\mathrm{AKT}$ ratio $(P<0.05)$.

\section{Expression of Muscle Growth-Related Genes}

The mRNA abundance of the longissimus dorsi muscle growth-related genes is shown in Figures 3A,B. Dietary MET supplementation increased the mRNA expression of myogenic factor 6 (Myf6; $P<0.05)$, MyoD1 $(P<0.05)$, and paired box gene 7 (Pax7; $P<0.05)$ and reduced the mRNA expression of myostatin (MSTN; $P<0.05)$. The mRNA expression of Pax3 $(P<0.05)$ and Myog $(P=0.057)$ was increased in the longissimus dorsi muscle of MET compared to the CON newborn piglets. Maternal MET supplementation significantly upregulated the mRNA expression of Myf5 $(P<0.05)$ and 
A

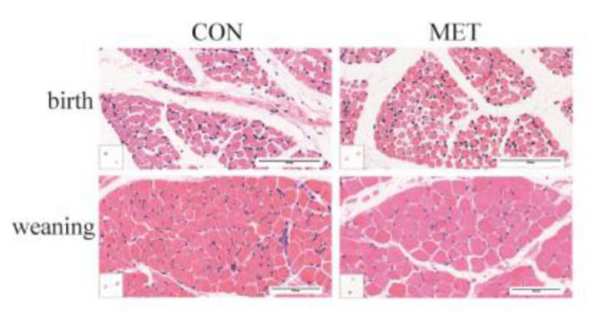

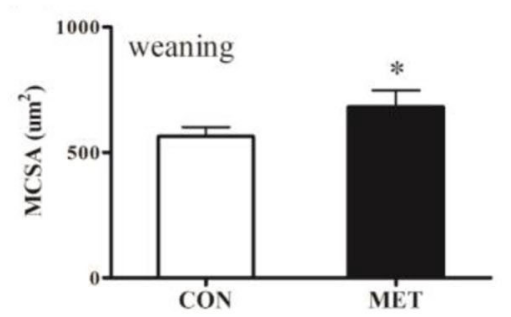

C

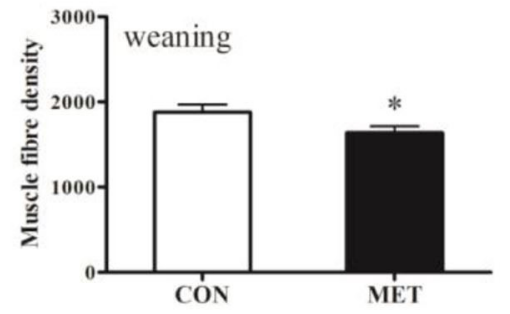

FIGURE 1 | Effects of maternal MET supplementation during gestation on histological properties in offspring longissimus dorsi muscle. Data are reported as means \pm standard deviation, $n=12$ at birth; $n=8$ at weaning. (A) Representative hematoxylin and eosin (H\&E) staining of newborn and weaning piglets. (B) Number of muscle fibers per $\mathrm{mm}^{2}$ of weaning offspring. (C) Muscle fiber cross-sectional area of weaning offspring. CON, control diet; MET, methyl-donor micronutrients diet. ${ }^{\star} P<0.05$ (significant differences between MET vs. CON).

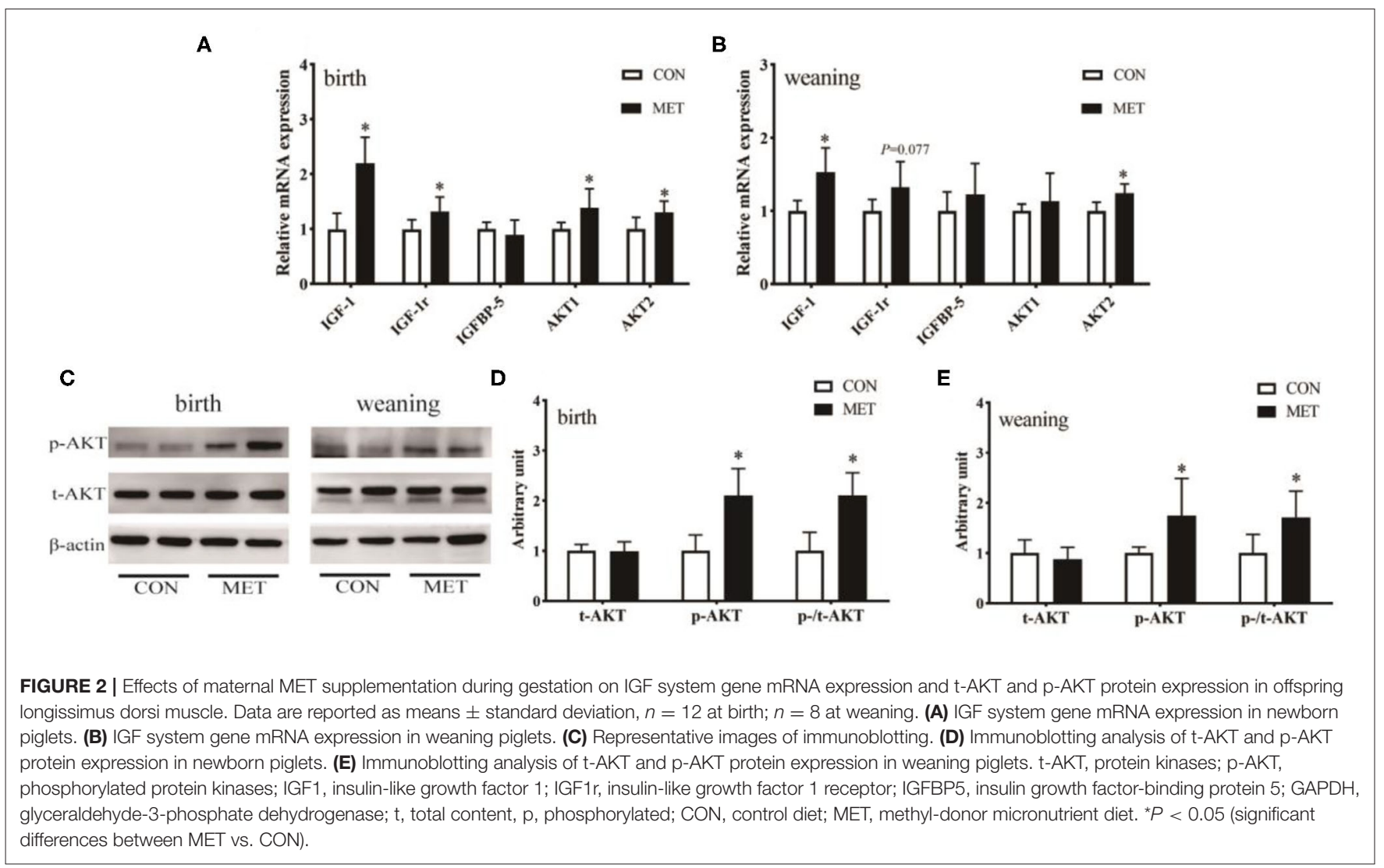

muscle regulatory factor 4 (MRF4; $P<0.05)$ in the weaning offspring. Western blotting further indicated that the protein expression of MyoD1 and Myog $(P<0.05)$ was significantly increased in the weaning offspring with maternal exposure to MET (Figures 3C-E). In addition, Myog protein expression of the newborn offspring tended to be increased in the MET group $(P=0.063)$.

\section{Expression of Muscle Fiber Type-Related Genes}

The mRNA abundance of MYH7 $(P<0.05)$, MYH2 $(P<0.05)$, and MYH1 $(P<0.05)$ was increased in the longissimus dorsi muscle in the MET compared to the CON newborn piglets
(Figure 4A). Prenatal MET exposure increased the mRNA expression of MYH2 $(P<0.05)$, MYH1 $(P<0.05)$, and MYH4 $(P<0.05)$ in the weaning offspring (Figure 4B). Consistent with their mRNA expression, there was no significant difference in the protein expression of the fast $\mathrm{MyHC}$ isoform in the newborn piglets $(P>0.05)$. However, the protein expression of the fast $\mathrm{MyHC}$ isoform in weaning piglets was upregulated in the treated group than in the control group $(P<0.05$; Figures $4 \mathrm{C}-\mathbf{E})$.

\section{DISCUSSION}

In our study, maternal MET exposure during pregnancy increased protein, T3, and T4 concentrations in colostrum 

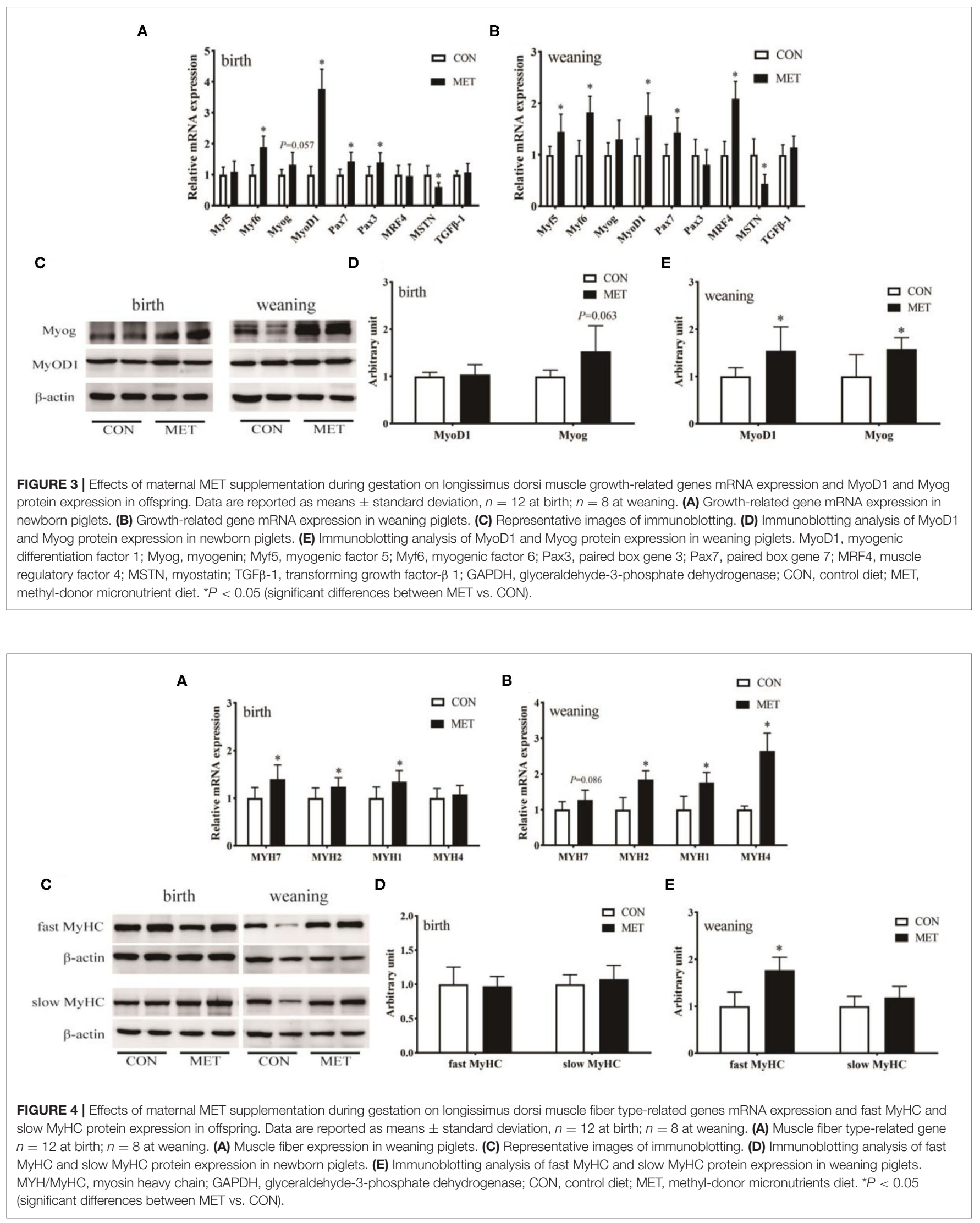
and methyl metabolites, including SAM, SAH, 5-MTHF, and betaine, in maternal and offspring umbilical vein serum. Similar findings were recorded in offspring BW gain and myofiber diameters. Meanwhile, maternal MET supplementation significantly increased the concentration of serum IGF-1, T3, and T4 in the offspring, decreased the concentration of maternal and offspring umbilical vein serum Hcy, and upregulated the mRNA expression of IGF-1 and IGF-1r and the phosphorylation level of AKT in the longissimus dorsi muscle of the offspring. Furthermore, maternal exposure to MET during pregnancy promoted skeletal muscle differentiation and maturity in pig offspring. We found no differences in the reproduction performance of the sows, which was similar to findings from a study by Zhao et al. (9). Some studies also found either a negative or no relationship between MET and fetal growth $(26,27)$. In betaine-supplemented dams, the first filial generation litter weights were smaller at birth and weaning, whereas the second filial generation had exactly the reverse effect in weaning (6). To date, the effect of maternal MET exposure during gestation on the growth performance of pig offspring has been controversial. However, maternal nutrition during pregnancy has been found to affect offspring development and has a profound effect throughout the life of the offspring via epigenetic modifications $(28,29)$. Thus, we speculate that the main reason for the different results is the different types and doses of MET.

Colostrum plays a major role in the survival of piglets during farrowing by not only providing heat and metabolic energy but also preventing infections through passive immunity. However, there are many factors affecting colostrum production, including genotype, parity, age, nursing behavior, and litter characteristics (30). To minimize the potential impact of sow condition on lactation performance, we used primiparous sow with similar genetic background and BW. Previously, it was reported that low-colostrum-producing sows have greater concentrations of progesterone and colostrum production in primiparous sows was positively associated with prolactin concentration (31). In our study, serum obtained from MET-fed sows had higher prolactin content than that obtained from CON-fed sows, which means sows could produce more milk to meet the needs of piglets. Meanwhile, colostrum obtained from MET-fed sows had higher protein content than that obtained from CON-fed sows. Because colostrum components are synthesized as early as a few weeks before farrowing, milk composition in colostrum is largely dependent on maternal body conditions (32). Previous studies have reported that methionine is an essential amino acid that may play a major role in swine protein structure and metabolism (33) and maintain the health of the sows (34). Methionine is a potential regulator of milk protein synthesis; it may easily restrict mammary protein synthesis (35). Furthermore, MET participates in the synthesis of nucleotides, proteins, and lipids by integrating glucose, amino acid status, and vitamins and feeds into epigenetic mechanisms by methyl group donation or transfer (8). These are also the main reasons for the increase in colostrum protein. Colostrum contains both nutrients and bioactive molecules. The concentration of the bioactive molecule in colostrum is closely related to the metabolic status of the sow during the perinatal and postnatal periods. We found higher T3, T4, and IgM in colostrum from MET-fed sows. Maternal MET exposure during pregnancy may promote mammary gland development of gilt and further increase the amount and quality of lactation, which lead to the offspring getting more adequate nutrition, promote skeletal muscle differentiation and maturity, and, ultimately, improve the growth performance of the offspring.

Previously, it was reported that an imbalance of methionine content in maternal diet will reduce the postnatal growth in rats (36). If the supply of methionine exceeds the maximum amount the animal can withstand, it may cause toxicities, such as hyperhomocysteinemia (a thrombogenic non-proteinogenic amino acid) and endothelial dysfunction. Hcy is a demethylated derivative of methionine that is produced during the onecarbon metabolism cycle. SAM is the most important metabolic substrate in methylation and participates in most methylation in animals (37). We found significantly higher serum SAM and SAH concentrations in sows and offspring umbilical vein of the MET group compared with the CON group. Folic acid supplementation was effective in reducing the total homocysteine levels (38). Reduced levels of serum Hcy in MET sows and the newborn pigs may be related to the increase in serum 5-MTHF concentration, which is the substrate of Hcy remethylation to methionine (39).

Dietary supplementation of methyl donors has been shown to promote Hcy metabolism. Moreover, changes in serum Hcy have been negatively correlated with IGF-I (40). Growth hormone $(\mathrm{GH})$ stimulates protein synthesis, and IGFs are essential for the rapid proliferation and differentiation of most tissues in animals (41). Furthermore, skeletal muscle is a major insulin target. The thicker muscle fiber diameter of the weaning offspring demonstrates that maternal MET exposure may improve the growth and formation of offspring fibers. We speculated that the offspring growth might be associated with muscle IGF signaling because maternal MET supplementation significantly increased the serum IGF-1 level of the offspring at birth. Additionally, we found that maternal exposure to MET increased offspring serum T3 and T4 concentrations, which are major factors in piglet muscle development (42). Moreover, we found a significantly upregulated mRNA expression of IGF-1 in offspring longissimus dorsi muscle in the MET group. Protein expression indicated that MET offspring had a significantly higher $\mathrm{p}-/ \mathrm{t}$-AKT ratio. AKT activation negatively regulates numerous pro-apoptotic factors and positively regulates the transcription factor, $\mathrm{MyoD}$, in myoblast cells, inducing terminal differentiation into myocytes and then fusion to regenerate myofibers $(43,44)$.

Myogenesis is a multistep process, including myoblast proliferation and differentiation, from precursor determination to patterning, differentiation, fusion, and maturation of muscle fiber types (45). It is crucial for muscle growth and regeneration after delivery. Pax3 and Pax7 are important regulators of myogenic progenitor cells, which can directly act upstream of myogenic regulatory factors (MRFs) to further promote muscle differentiation and growth $(46,47)$. MRFs include MyoD1, Myf5, Myog, and MRf4 (48). MyoD1 and Myf5 are involved in muscle determination, while Myog plays a predominant role in muscle cell differentiation to form muscle fibers. MRF4 is essential in the maintenance of postnatal muscles (49). MSTN 
is a negative regulator of skeletal muscle growth (50). After birth, muscle growth and development are mainly based on the increase of the muscle fiber area (51), Myogenesis promotes muscle fiber hypertrophy and growth by maintaining the proliferation and differentiation of the muscle satellite cells (3). The present results showed that the diameter of muscle fiber in weaning pigs in the MET group was thicker than that in the CON group. Furthermore, the mRNA expression of Myf5, MyoD1, MRF4, Myog, and Pax7 was increased and the protein expression of Myog was upregulated in weaning pigs in the MET group, suggesting that MET supplementation during gestation improved myogenesis and promoted muscle fiber hypertrophy and growth. We also noted that maternal MET supplementation during gestation increased MRF4 mRNA in weaning offspring. This was similar to findings from a previous study, which showed that MRF4 expression increased during hypertrophy induced by a high level of methionine administration in mice (52). However, although we did not measure the levels of MRF4 protein, it is tempting to infer that the increased level of MRF4 mRNA was probably associated with postpartum skeletal muscle hypertrophy and growth upon MET administration in sows.

Generally, skeletal muscle fiber types are characterized in part by the expression of multiple MYH genes (53). Muscle fiber types can be classified into slow MyHC and fast $\mathrm{MyHC}$. We found that gestational MET increased MYH2, MYH1, and MYH4 mRNA expression and upregulated fast MyHC protein expression in weaning offspring, indicating that gestational MET caused early muscle differentiation leading to a higher degree of muscular maturity during weaning. Consistent with Senesi's et al. (54) findings, betaine supplementation enhanced skeletal muscle differentiation via IGF activation. The increased fast-twitch myofiber isoform in MET weaning piglets was also linked to serum T3 and T4 in our study. The thyroid hormone is a major determinant of myofiber composition, which can promote the uptake and utilization of glucose by muscle tissue and regulate the conversion of embryonic or prenatal $\mathrm{MyHC}$ isoforms to adult fast MyHC isoforms (42). Muscle differentiation is a process from slow-twitch myofibers to fasttwitch myofibers. MET regulates the expression of myogenesisrelated genes through DNA methylation, thereby regulating the proliferation and differentiation of myoblast (55). It can significantly increase the concentrations of $5-\mathrm{mC}$ and $6-\mathrm{mA}$ than affect DNA methylation levels in C2C12 myoblasts (18, 56). However, we failed to measure the degree of methylation of the gene promoter. Nonetheless, according to the number of methyl metabolites and gene expression, we speculate that maternal MET exposure during pregnancy may promote skeletal muscle differentiation and maturity in offspring through the upregulation of the muscle gene expression of IGFs.

\section{REFERENCES}

1. Liu HY, Liu SM, Zhang YZ. Maternal folic acid supplementation mediates offspring health via DNA methylation. Reprod Sci. (2020) 27:963-76. doi: $10.1007 / \mathrm{s} 43032-020-00161-2$

\section{CONCLUSION}

In summary, maternal MET exposure during pregnancy promoted the differentiation and maturity of skeletal muscle in pig offspring, which was associated with improved colostrum quality (protein, Ig, T3, and T4); a higher concentration of IGF-1, T3, SAM, SAH, and 5-MTHF; and lower Hcy level in offspring serum and upregulated expression of myogenic genes and fast $\mathrm{MyHC}$ in offspring skeletal muscle. These results suggest that supplementing sows with higher MET during gestation can promote skeletal muscle differentiation and maturity and improve the skeletal muscle mass of piglets.

\section{DATA AVAILABILITY STATEMENT}

The original contributions presented in the study are included in the article/supplementary material, further inquiries can be directed to the corresponding author/s.

\section{ETHICS STATEMENT}

The animal study was reviewed and approved by the experiment was conducted following the Chinese guidelines for animal welfare. All experimental procedures using laboratory animals were approved by the Animal Care and Use Committee of Jiangxi Agricultural University (Ethics Approval Code: JXAUA01).

\section{AUTHOR CONTRIBUTIONS}

JY and TZ contributed to experimental concepts and design. $\mathrm{QH}, \mathrm{LJ}$, and $\mathrm{JH}$ performed the animal feeding experiment and sample analysis. ZW, FX, and YX assisted with immunoblotting analysis and the detection of the serum level of hormones. QH analyzed the data and wrote the manuscript. JY, TZ, and JC finalized the manuscript. All authors read and approved the final manuscript.

\section{FUNDING}

This work was supported by the National Key Research and Development Program of China (2018YFD0500401) and Project funded by the China Postdoctoral Science Foundation (2019M662270).

\section{ACKNOWLEDGMENTS}

We would like to thank Freescience (https://www.home-forresearchers.com) for the English language editing.

2. Richmond RC, Sharp GC, Herbert G, Atkinson C, Taylor C, Bhattacharya $\mathrm{S}$, et al. The long-term impact of folic acid in pregnancy on offspring DNA methylation: follow-up of the aberdeen folic acid supplementation trial (AFAST). Int J Epidemiol. (2018) 47:928-37. doi: 10.1093/ije/ dyy032 
3. Zou T, He D, Yu B, Yu J, Mao X, Zheng P, et al. Moderately increased maternal dietary energy intake delays foetal skeletal muscle differentiation and maturity in pigs. Eur J Nutr. (2016) 55:1777-87. doi: 10.1007/s00394-0150996-9

4. Henderson AM, Tai DC, Aleliunas RE, Aljaadi AM, Glier MB, Xu EE, et al. Maternal folic acid supplementation with vitamin B12 deficiency during pregnancy and lactation affects the metabolic health of adult female offspring but is dependent on offspring diet. FASEB J. (2018) 32:5039-50. doi: 10.1096/fj.201701503RR

5. Zhang X, Li H, Liu G, Wan H, Mercier Y, Wu C, et al. Differences in plasma metabolomics between sows fed DL-methionine and its hydroxy analogue reveal a strong association of milk composition and neonatal growth with maternal methionine nutrition. Br J Nutr. (2015) 113:585-95. doi: $10.1017 /$ S0007114514004036

6. Zhao N, Yang S, Hu Y, Dong H, Zhao R. Maternal betaine supplementation in rats induces intergenerational changes in hepatic IGF-1 expression and DNA methylation. Mol Nutr Food Res. (2017) 61:1600437. doi: $10.1002 / \mathrm{mnfr} .201600940$

7. Yu B, Yang G, Liu J, Chen D. Effects of folic acid supplementation on growth performance and hepatic folate metabolism-related gene expressions in weaned piglets. Front Agric China. (2010) 4:494-500. doi: 10.1007/s11703-010-1047-1

8. Yu W, Wang Z, Zhang $\mathrm{K}$, Chi Z, Xu T, Jiang D, et al. One-Carbon metabolism supports $\mathrm{S}$-adenosylmethionine and histone methylation to drive inflammatory macrophages. Mol Cell. (2019) 75:1147-60. doi: 10.1016/j.molcel.2019.06.039

9. Zhao Y, Jin C, Xuan Y, Zhou P, Fang Z, Che L, et al. Effect of maternal or post-weaning methyl donor supplementation on growth performance, carcass traits, and meat quality of pig offspring. J Sci Food Agr. (2019) 99:2096-107. doi: $10.1002 /$ jsfa. 9402

10. Soares RJ, Cagnin S, Chemello F, Silvestrin M, Musaro A, De Pitta CCDU, et al. Involvement of MicroRNAs in the regulation of muscle wasting during catabolic conditions. J Biol Chem. (2014) 32:21909-25. doi: $10.1074 /$ jbc.M114.561845

11. Roberts TC, Etxaniz U, Dall'Agnese A, Wu SY, Chiang CM, Brennan PE, et al. BRD3 and BRD4 BET bromodomain proteins differentially regulate skeletal myogenesis. Sci Rep. (2017) 7:6153-68. 10.1038/s41598-017-06483-7. doi: 10.1038/s41598-017-06483-7

12. Zhu MJ, Ford SP, Means WJ, Hess BW, Nathanielsz PW, Du M. Maternal nutrient restriction affects properties of skeletal muscle in offspring. J Physiol. (2006) 575:241-50. doi: 10.1113/jphysiol.2006.112110

13. Wang B, Li H, Li Z, Jian L, Gao Y, Qu Y, et al. Maternal folic acid supplementation modulates the growth performance, muscle development and immunity of $\mathrm{Hu}$ sheep offspring of different litter size. J Nutr Biochem. (2019) 70:194-201. doi: 10.1016/j.jnutbio.2019.05.011

14. Geoffroy A, Saber-Cherif L, Pourié G, Helle D, Umoret R, Guéant J, et al. Developmental impairments in a rat model of methyl donor deficiency: effects of a late maternal supplementation with folic acid. Int J Mol Sci. (2019) 20:973-86. doi: 10.3390/ijms20040973

15. Wu S, Zhang J, Li F, Du W, Zhou X, Wan M, et al. One-Carbon metabolism links nutrition intake to embryonic development via epigenetic mechanisms. Stem Cells Int. (2019) 2019:3894101. doi: 10.1155/2019/3894101

16. Barnett MPG, Bermingham EN, Young W, Bassett SA, Hesketh JE, MacielDominguez A, et al. Low folate and selenium in the mouse maternal diet alters liver gene expression patterns in the offspring after weaning. Nutrients. (2015) 7:3370-86. doi: 10.3390/nu7053370

17. Bibbins-Domingo K, Grossman DC, Curry SJ, Davidson KW, Epling JW, García FAR, et al. Folic acid supplementation for the prevention of neural tube defects: US preventive services task force recommendation statement. JAMA. (2017) 317:183-9. doi: 10.1001/jama.2016.19438

18. Du J, Shen L, Zhang P, Tan Z, Cheng X, Luo J, et al. The regulation of skeletal muscle fiber-type composition by betaine is associated with NFATc1/MyoD. J Mol Med. (2018) 96:685-700. doi: 10.1007/s00109-018-1657-2

19. Oster M, Nuchchanart W, Trakooljul N, Murani E, Zeyner A, Wirthgen E, et al. Methylating micronutrient supplementation during pregnancy influences foetal hepatic gene expression and IGF signalling and increases foetal weight. Eur J Nutr. (2016) 55:1717-27. doi: 10.1007/s00394-015-0990-2
20. Haggarty P, Hoad G, Campbell DM, Horgan GW, Piyathilake C, McNeill G. Folate in pregnancy and imprinted gene and repeat element methylation in the offspring. Am J Clin Nutr. (2013) 97:94-9. doi: 10.3945/ajcn.112.042572

21. National Research Council (US). Nutrient Requirements of Swine (11th rev.). Washington, DC: National Research Council (US) (2012).

22. Guay F, Matte JJ, Girard CL, Palin MF, Giguere A, Laforest JP. Effect of folic acid and glycine supplementation on embryo development and folate metabolism during early pregnancy in pigs. J Anim Sci. (2002) 80:2134-43. doi: $10.1093 /$ ansci/80.8.2134

23. Matte JJ, Guay F, Girard CL. Folic acid and vitamin B 12 in reproducing sows: new concepts. Can J Anim Sci. (2006) 86:197-205. doi: 10.4141/A05-059

24. Oster M, Trakooljul N, Reyer H, Zeyner A, Muráni E, Ponsuksili S, et al. Sex-Specific muscular maturation responses following prenatal exposure to methylation-Related micronutrients in pigs. Nutrients. (2017) 9:74-85. doi: $10.3390 /$ nu 9010074

25. Livak KJ, Schmittgen TD. Analysis of relative gene expression data using realtime quantitative PCR and the $2^{-\Delta \Delta C T}$ method. Methods. (2001) 25:402-8. doi: $10.1006 /$ meth.2001.1262

26. Hogeveen M, Blom HJ, Heijden EHVD, Semmekrot BA, Sporken JM, Ueland PM, et al. Maternal homocysteine and related B vitamins as risk factors for low birthweight. Am J Obstet Gynecol. (2010) 202:572.e1-6. doi: 10.1016/j.ajog.2010.01.045

27. Huot PSP, Dodington DW, Mollard RC, Reza-López SA, Sánchez-Hernández D, Cho CE, et al. High folic acid intake during pregnancy lowers body weight and reduces femoral area and strength in female rat offspring. J Osteoporos. (2013) 2013:154109. doi: 10.1155/2013/154109

28. Zhuo Y, Wang J, Liu H, Mou D, Adebowale T, Che L, et al. Effects of maternal methyl donor on the pork characteristics of offspring pigs with prenatal exposure to bisphenol A. Animal. (2018) 12:1306-15. doi: $10.1017 /$ S175173111700252X

29. Fleisch AF, Rifas-Shiman SL, Rokoff LB, Hivert MF, Mantzoros CS, Oken E. Associations of maternal prenatal smoking with umbilical cord blood hormones: the project viva cohort. Metabolism. (2017) 72:18-26. doi: 10.1016/j.metabol.2017.04.001

30. Farmer C, Quesnel H. Nutritional, hormonal, and environmental effects on colostrum in sows. J Anim Sci. (2009) 87:56-64. doi: 10.2527/jas.20 08-1203

31. Foisnet A, Farmer C, David C, Quesnel H. Relationships between colostrum production by primiparous sows and sow physiology around parturition. J Anim Sci. (2010) 88:1672-83. doi: 10.2527/jas.2009-2562

32. Wang J, Yang M, Cao M, Lin Y, Che L, Duraipandiyan V, et al. Moderately increased energy intake during gestation improves body condition of primiparous sows, piglet growth performance, and milk fat and protein output. Livest Sci. (2016) 194:23-30. doi: 10.1016/j.livsci.2016.09.012

33. Brosnan JT, Brosnan ME, Bertolo RFP, Brunton JA. Methionine: a metabolically unique amino acid. Livest Sci. (2007) 112:2-7. doi: 10.1016/j.livsci.2007.07.005

34. Bin P, Azad MAK, Liu G, Zhu D, Kim SW, Yin Y. Effects of different levels of methionine on sow health and plasma metabolomics during late gestation. Food Funct. (2018) 9:4979-88. doi: 10.1039/C8FO01477A

35. Appuhamy JADR, Knoebel NA, Nayananjalie WAD, Escobar J, Hanigan MD. Isoleucine and leucine independently regulate mTOR signaling and protein synthesis in MAC-T cells and bovine mammary tissue slices. J Nutr. (2012) 142:484-91. doi: 10.3945/jn.111.152595

36. Rees WD, Hay SM, Cruickshank M. An imbalance in the methionine content of the maternal diet reduces postnatal growth in the rat. Metabolism. (2006) 55:763-70. doi: 10.1016/j.metabol.2006.01.012

37. Stipanuk MH, Ueki I. Dealing with methionine/homocysteine sulfur: cysteine metabolism to taurine and inorganic sulfur. J Inherit Metab Dis. (2011) 34:17-32. doi: 10.1007/s10545-009-9006-9

38. Tinelli C, Pino AD, Ficulle E, Marcelli S, Feligioni M. Hyperhomocysteinemia as a risk factor and potential nutraceutical target for certain pathologies. Front Nutr. (2019) 6:49. doi: 10.3389/fnut.2019.00049

39. George AK, Majumder A, Ice H, Homme RP, Eyob W, Tyagi SC, et al. Genes and genetics in hyperhomocysteinemia and the "1-carbon metabolism": implications for retinal structure and eye functions. Can J Physiol Pharm. (2020) 98:51-60. doi: 10.1139/cjpp-2019-0236 
40. Sesmilo G, Biller BM, Llevadot J, Hayden D, Hanson G, Rifai N, et al. Effects of growth hormone $(\mathrm{GH})$ administration on homocyst(e)ine levels in men with GH deficiency: a randomized controlled trial. J Clin Endocrinol Metab. (2001) 86:1518-24. doi: 10.1210/jc.86.4.1518

41. Bowman CJ, Streck RD, Chapin RE. Maternal-placental insulin-like growth factor (IGF) signaling and its importance to normal embryo-fetal development. Birth Defects Res B Dev Reprod Toxicol. (2010) 89:339-49. doi: 10.1002/bdrb.20249

42. Zhang D, Wang X, Li Y, Zhao L, Lu M, Yao X, et al. Thyroid hormone regulates muscle fiber type conversion via miR-133a1. J Cell Biol. (2014) 207:753-66. doi: $10.1083 /$ jcb. 201406068

43. Mnatsakanyan H, Serra RSI, Rico P, Salmerón-Sánchez M. Zinc uptake promotes myoblast differentiation via Zip7 transporter and activation of Akt signalling transduction pathway. Sci Rep. (2018) 8:13642. doi: 10.1038/s41598-018-32067-0

44. Zhang $\mathrm{Y}, \mathrm{Wu} \mathrm{Z}$, Yu H, Wang $\mathrm{H}$, Liu G, Wang S, et al. Chinese herbal medicine wenxia changfu formula reverses cell adhesion-Mediated drug resistance via the integrin $\beta 1$-PI3K-AKT pathway in lung cancer. J Cancer. (2019) 10:293-304. doi: 10.7150/jca.25163

45. Schnapp E, Pistocchi AS, Karampetsou E, Foglia E, Lamia CL, Cotelli F, et al. Induced early expression of mrf4 but not myog rescues myogenesis in the myod/myf5 double-morphant zebrafish embryo. J Cell Sci. (2009) 122:481-88. doi: $10.1242 /$ jcs. 038356

46. Bajard L. A novel genetic hierarchy functions during hypaxial myogenesis: Pax3 directly activates Myf5 in muscle progenitor cells in the limb. Gene Dev. (2006) 20:2450-64. doi: 10.1101/gad.382806

47. McKinnell IW, Greenblatt JF, Rudnicki MA, Addicks GC, Dilworth FJ, Ishibashi J, et al. Pax7 activates myogenic genes by recruitment of a histone methyltransferase complex. Nat Cell Biol. (2008) 10:77-84. doi: $10.1038 /$ ncb1671

48. Chen R, Wen C, Cheng Y, Zhuang S, Zhou Y. Effects of dietary supplementation with betaine on muscle growth, muscle amino acid contents and meat quality in cherry valley ducks. J Anim Physiol An N. (2019) 103:1050-59. doi: 10.1111/jpn.13083

49. Choi DH, Yang J, Kim YS. Rapamycin suppresses postnatal muscle hypertrophy induced by myostatin-inhibition accompanied by transcriptional suppression of the Akt/mTOR pathway. Biochem Biophys Rep. (2019) 17:18290. doi: 10.1016/j.bbrep.2018.12.009

50. Lee SJ, McPherron AC. Regulation of myostatin activity and muscle growth. Proc Natl Acad Sci USA. (2001) 98:9306-11. doi: 10.1073/pnas.151270098

51. Du M, Zhao JX, Yan X, Huang Y, Nicodemus LV, Yue W, et al. Fetal muscle development, mesenchymal multipotent cell differentiation, and associated signaling pathways. J Anim Sci. (2011) 98:583-90. doi: 10.2527/jas.2010-3386

52. Loughna PT, Brownson C. Two myogenic regulatory factor transcripts exhibit muscle-specific responses to disuse and passive stretch in adult rats. FEBS Lett. (1996) 390:304-6. doi: 10.1016/0014-5793(96)00681-3

53. Chang K. Postnatal myosin heavy chain isoforms in prenatal porcine skeletal muscles: insights into temporal regulation. Ana Rec A Discov Mol Cell Evol Biol. (2003) 273:731-40. doi: 10.1002/ar.a.10083

54. Senesi PA, Luzi LAB, Montesano AA, Mazzocchi NC, Terruzzi IC, Betaine supplement enhances skeletal muscle differentiation in murine myoblasts via IGF-1 signaling activation. J Transl Med. (2013) 11:174-85. doi: 10.1186/1479-5876-11-174

55. Lucarelli M, Fuso A, Strom R. The dynamics of myogenin site-specific demethylation is strongly correlated with its expression and with muscle differentiation. J Biol Chem. (2001) 276:7500-6. doi: 10.1074/jbc.M008234200

56. Zhou X, Chen J, Chen J, Wu W, Wang X, Wang Y. The beneficial effects of betaine on dysfunctional adipose tissue and N6-methyladenosine mRNA methylation requires the AMP-activated protein kinase $\alpha 1$ subunit. $J$ Nutr Biochem. (2015) 26:1678-84. doi: 10.1016/j.jnutbio.2015.08.014

Conflict of Interest: The authors declare that the research was conducted in the absence of any commercial or financial relationships that could be construed as a potential conflict of interest.

Copyright (๑) $2020 \mathrm{He}$, Zou, Chen, Jian, He, Xia, Xie, Wang and You. This is an open-access article distributed under the terms of the Creative Commons Attribution License (CC BY). The use, distribution or reproduction in other forums is permitted, provided the original author(s) and the copyright owner(s) are credited and that the original publication in this journal is cited, in accordance with accepted academic practice. No use, distribution or reproduction is permitted which does not comply with these terms. 